\title{
Eye care utilization among diabetics in the South African National Health and Nutrition Examination Survey (SANHANES-1): a cross-sectional study
}

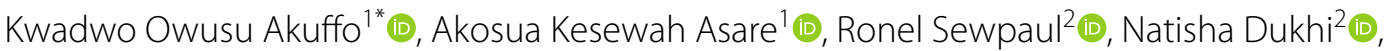

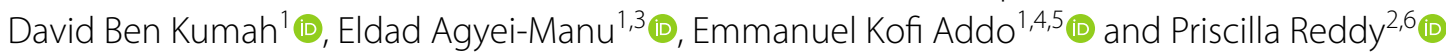

\begin{abstract}
Objective: Diabetes is a chronic disease of uncontrolled blood sugar levels. People with diabetes are at an increased risk of developing visual impairment and other diabetes-related visual complications. The study aims to determine the eyecare utilization pattern and its associated determinants among diabetics in the South African National Health and Nutrition Examination Survey (SANHANES-1).

Results: The mean age of participants was 56.2 years and $66.6 \%$ were females. The prevalence of eyecare utilization among participants was $49.0 \%$ and this differed significantly by age groups $(p=0.024)$ and the number of years since diabetes diagnosis $(p<0.001)$. After statistical adjustments, older age ( $55-64$ years $O R=4.18, p=0.003$ and $\geq 65$ years $\mathrm{OR}=4.78, \mathrm{p}=0.002)$, having health insurance $(\mathrm{OR}=6.32, \mathrm{p}=0.002)$, and having had diabetes for $6-10$ years $(\mathrm{OR}=4.23, \mathrm{p}=0.005)$ were significantly associated with eye care utilization. About half of people diagnosed with diabetes in South Africa have had an eye examination since diabetes diagnosis, which is disturbingly low given the impact of diabetes complications on eye health. Government policies must be directed at ensuring access to affordable health insurance and eye health education on diabetes.
\end{abstract}

Keywords: Eye care utilization, Diabetes, Population-based, South Africa, Sociodemographic characteristics, Highrisk, Barriers, Disparities, Eye Care Services

\section{Introduction}

Globally, diabetes and its complications are major public health problems [1], with an increasing burden of blindness and vision loss [2], as well as potential financial loss to individuals and nations [3]. People with diabetes have higher risks of developing cataracts, glaucoma, dry eyes and retinopathy [4-6] in comparison to the general population.

\footnotetext{
*Correspondence: akuffokwadwoowusu@knust.edu.gh; koakuffo@gmail.com ${ }^{1}$ Department of Optometry and Visual Science, College of Science, Kwame Nkrumah University of Science and Technology, Kumasi, Ghana Full list of author information is available at the end of the article
}

The South African National Health and Nutrition Examination Survey (SANHANES-1) was established as a nationally representative population health survey to address epidemiological transition and the changing health needs of South Africans [7]. The survey found that the prevalence of inpatient and outpatient health care utilization was $20.1 \%$ and $27 \%$ respectively, and further reported chronic conditions (including diabetes) as reasons for the utilization of the health care services [7]. Considering the adverse effects of diabetes on the eye, people with diabetes have a greater need for ophthalmic care and are expected to utilize eyecare services more frequently than the general population. These bring to

(c) The Author(s) 2020. This article is licensed under a Creative Commons Attribution 4.0 International License, which permits use, sharing, adaptation, distribution and reproduction in any medium or format, as long as you give appropriate credit to the original author(s) and the source, provide a link to the Creative Commons licence, and indicate if changes were made. The images or other third party material in this article are included in the article's Creative Commons licence, unless indicated otherwise in a credit line to the material. If material is not included in the article's Creative Commons licence and your intended use is not permitted by statutory regulation or exceeds the permitted use, you will need to obtain permission directly from the copyright holder. To view a copy of this licence, visit http://creativeco mmons.org/licenses/by/4.0/. The Creative Commons Public Domain Dedication waiver (http://creativecommons.org/publicdomain/ zero/1.0/) applies to the data made available in this article, unless otherwise stated in a credit line to the data. 
fore the need to investigate the pattern of eye care utilization in this populace.

The purpose of this study therefore was: (1) to determine the eye care utilization patterns among people with diabetes in South Africa using data from SANHANES-1; and (2) to identify factors that influence the utilization of eye care services (i.e., sociodemographic or healthrelated factors correlates to eye care utilization). Secondary data analyses from this nationally representative study will contribute immensely to stakeholder policies on diabetic care and in general, eye care services and its delivery.

\section{Main text \\ Participants and methods \\ Data and sample}

This population-based (cross-sectional) study used data on self-reporting diabetic participants from the SANHANES-1 (a national survey conducted in 2011-2012). The survey used multi-stage disproportionate, stratified cluster sampling to select households within enumeration areas (EAs) stratified by province and locality types, where 10,000 occupied households were selected. Within the occupied households, 27,580 individuals of all ages were eligible to be interviewed and agreed to participate in the study. However, only 25,532 (92.6\%) completed the interview. Of the latter number, 12,025 (43.6\%) individuals volunteered to undergo a medical examination of which 7455 were aged 15 years or older. A detailed description of the SANHANES-1 methodology has been previously reported [7].

Analyses were conducted on individuals aged $\geq 15$ years who reported having been diagnosed with diabetes and who underwent the medical examination, where a clinician assessed their vision and measured their BMI and blood pressure. To investigate the association of all the predisposing, enabling and need factors on having had an eye examination, the analytic sample was based on individuals who had non-missing responses to all the independent variables.

\section{Measures}

Eye care utilization was assessed from participants' responses to the following question: "Since you were diagnosed with diabetes, have you ever had your eyes examined? This is an examination during which your pupils are usually dilated. It can make you temporarily sensitive to bright light." The individual factors associated with having an eye examination were investigated using Andersen's Behavioural Model [8]. According to this model, variables were categorized into predisposing, enabling, and need factors.

\section{Data analysis}

Data were analysed in Stata 15.0. (StataCorp, Texas, USA 2016). The analyses applied sample weights to adjust for unequal probabilities of selection and nonresponse. The prevalence of having had an eye examination/s since diabetes diagnosis was presented by categories of the independent variables and difference between categories of a variable were tested using Chi square tests. Three multiple logistic regression models were used to investigate the predisposing, enabling and need factors associated with the outcome; having ever had an eye examination since being diagnosed with diabetes. Andersen's model was applied in the multiple logistic regression models, where the predisposing, enabling and need factors were added sequentially. Model 1 included only the predisposing factors, Model 2, the predisposing and enabling factors and Model 3 included the predisposing, enabling and need factors.

\section{Results}

\section{Description of the sample}

Table 1 shows the demographic and lifestyle characteristics of the analytic sample (i.e. diabetics who underwent the physical examination including vision loss assessment with available data on all factors).

\section{Eye care utilization among people with diabetes}

Overall, $49.0 \%$ of people with diabetes reported having ever had an eye examination since their diabetes diagnosis (Table 2). The prevalence of having an eye examination since diagnosis differed significantly by age groups $(p=0.024)$ and the number of years since diabetes diagnosis $(p<0.001)$. It was significantly higher among those with health insurance than those without $(72.0 \%$ versus $43.8 \%, \mathrm{p}=0.003$ ) and among those with hypertension than without $(53.7 \%$ versus $36.6 \%, \mathrm{p}=0.034)$.

\section{Factors associated with eye care utilization among people with diabetes}

Model 1, with predisposing factors (Akaike's information Criteria (AIC): 750482.6, Prob $>\mathrm{F}=0.112$ ), showed that older age (55-64 years, odds ratio $(\mathrm{OR})=3.77, \mathrm{p}=0.007$ and $\geq 65$ years $\mathrm{OR}=3.68 \mathrm{p}=0.011$ compared with $15-44$ years) was significantly associated with having had an eye examination (Table 3 ).

In Model 2 (AIC: 692682.6, Prob $>\mathrm{F}=0.001$ ), which included predisposing and enabling factors, the associations with older age were similar to that of Model 1 . White or Indian ethnicity $(\mathrm{OR}=0.29, \mathrm{p}=0.046$ compared 
Table 1 Description of the analytic sample

\begin{tabular}{|c|c|c|}
\hline & $\%$ & Frequency \\
\hline Total & 100.0 & 325 \\
\hline Age (mean, S.D.) & 57.3 & 13.3 \\
\hline $15-44$ & 12.6 & 41 \\
\hline $45-54$ & 28.3 & 92 \\
\hline $55-64$ & 33.2 & 108 \\
\hline$\geq 65$ & 25.8 & 84 \\
\hline \multicolumn{3}{|l|}{ Sex } \\
\hline Males & 31.4 & 102 \\
\hline Females & 68.6 & 223 \\
\hline \multicolumn{3}{|l|}{ Ethnicity } \\
\hline African & 62.5 & 203 \\
\hline White & 2.2 & 7 \\
\hline 'Coloured'(mixed race) & 23.1 & 75 \\
\hline Indian & 12.3 & 40 \\
\hline High risk alcohol use & 11.7 & 38 \\
\hline Current smoker & 14.5 & 47 \\
\hline Body mass index (BMI) $\left(\mathrm{kg} / \mathrm{m}^{2}\right)$ (mean, S.D.) & 30.6 & 7.3 \\
\hline Underweight $<18.5 \mathrm{~kg} / \mathrm{m}^{2}$ & 3.4 & 11 \\
\hline Normal weight $18.5-24.9 \mathrm{~kg} / \mathrm{m}^{2}$ & 17.8 & 58 \\
\hline Overweight $25-29.9 \mathrm{~kg} / \mathrm{m}^{2}$ & 26.5 & 86 \\
\hline Obese $\geq 30 \mathrm{~kg} / \mathrm{m}^{2}$ & 52.3 & 170 \\
\hline \multicolumn{3}{|l|}{ Residence } \\
\hline Rural & 32.3 & 105 \\
\hline Urban & 67.7 & 220 \\
\hline Has health insurance & 17.5 & 57 \\
\hline Hypertensive & 77.5 & 252 \\
\hline High cholesterol & 23.4 & 76 \\
\hline Cardiovascular disease & 20.0 & 65 \\
\hline Accessed health care in past 5 years & 56.3 & 183 \\
\hline Clinician-assessed vision loss & 29.8 & 97 \\
\hline Self-reported vision problems & 43.4 & 141 \\
\hline \multicolumn{3}{|l|}{ Diabetic medication use } \\
\hline No medication & 16.3 & 53 \\
\hline Oral glycaemic medication & 54.8 & 178 \\
\hline Insulin & 3.7 & 12 \\
\hline Insulin and oral glycaemic medication & 25.2 & 82 \\
\hline $\begin{array}{l}\text { Number of years since diabetes diagnosis (mean, } \\
\text { S.D.) }\end{array}$ & 12.7 & 15.9 \\
\hline $0-5$ years & 45.5 & 148 \\
\hline $6-10$ years & 15.4 & 50 \\
\hline $11-20$ years & 19.4 & 63 \\
\hline$>20$ years & 19.7 & 64 \\
\hline
\end{tabular}

with African ethnicity) and being overweight $(\mathrm{OR}=0.40$, $\mathrm{p}=0.041$ compared with normal-weight or underweight) were associated with significantly reduced odds of having had an eye examination. Having health insurance $(\mathrm{OR}=6.98, \mathrm{p}<0.001)$ was significantly associated with increased odds of having had an eye examination.
Table 2 Prevalence of having ever had an eye examination since diabetes diagnosis

\begin{tabular}{|c|c|c|c|c|}
\hline & \multicolumn{4}{|c|}{$\begin{array}{l}\text { Had an eye examination } \\
\text { since diabetes diagnosis }\end{array}$} \\
\hline & $\%$ & $95 \% \mathrm{Cl}$ & $\mathrm{n}$ & $p$ value \\
\hline Overall & 49.0 & {$[41.4-56.6]$} & 325 & \\
\hline \multicolumn{5}{|l|}{ Predisposing factors } \\
\hline \multicolumn{5}{|l|}{ Age } \\
\hline 15-44 years & 31.0 & {$[16.3-50.8]$} & 41 & 0.024 \\
\hline $45-54$ years & 42.6 & {$[30.4-55.7]$} & 92 & \\
\hline $55-64$ years & 59.6 & {$[47.3-70.7]$} & 108 & \\
\hline$\geq 65$ years & 59.6 & {$[45.3-72.4]$} & 84 & \\
\hline \multicolumn{5}{|l|}{ Sex } \\
\hline Males & 50.0 & {$[37.5-62.4]$} & 102 & 0.857 \\
\hline Females & 48.5 & {$[39.3-57.8]$} & 223 & \\
\hline \multicolumn{5}{|l|}{ Ethnicity } \\
\hline African & 49.1 & {$[40.1-58.1]$} & 203 & 0.678 \\
\hline 'Coloured'(mixed race) & 53.1 & {$[38.8-67.0]$} & 75 & \\
\hline White or Indian & 41.6 & {$[24.4-61.2]$} & 47 & \\
\hline \multicolumn{5}{|l|}{ High risk alcohol use } \\
\hline Low risk & 49.0 & {$[40.9-57.2]$} & 287 & 0.996 \\
\hline High risk & 48.9 & {$[24.9-73.4]$} & 38 & \\
\hline \multicolumn{5}{|l|}{ Current smoker } \\
\hline No & 50.8 & {$[42.9-58.6]$} & 278 & 0.257 \\
\hline Yes & 37.5 & {$[19.6-59.5]$} & 47 & \\
\hline \multicolumn{5}{|l|}{ Body mass index (BMI) } \\
\hline $\begin{array}{l}\text { Underweight/normal } \\
\text { weight: }<25 \mathrm{~kg} / \mathrm{m}^{2}\end{array}$ & 46.5 & {$[31.5-62.1]$} & 69 & 0.764 \\
\hline Overweight: $25-29.9$ kg/m² & 45.9 & {$[32.7-59.7]$} & 86 & \\
\hline Obese: $\geq 30 \mathrm{~kg} / \mathrm{m}^{2}$ & 51.5 & {$[41.1-61.8]$} & 170 & \\
\hline \multicolumn{5}{|l|}{ Enabling factors } \\
\hline \multicolumn{5}{|l|}{ Residence } \\
\hline Rural & 45.9 & {$[34.4-57.9]$} & 105 & 0.525 \\
\hline Urban & 51.0 & {$[41.2-60.7]$} & 220 & \\
\hline \multicolumn{5}{|l|}{ Has health insurance } \\
\hline No & 43.8 & {$[35.5-52.4]$} & 268 & 0.003 \\
\hline Yes & 72.0 & {$[55.2-84.3]$} & 57 & \\
\hline \multicolumn{5}{|l|}{ Need factors } \\
\hline \multicolumn{5}{|l|}{ Hypertension } \\
\hline No & 36.6 & {$[24.5-50.6]$} & 73 & 0.034 \\
\hline Yes & 53.7 & {$[45.2-62.0]$} & 252 & \\
\hline \multicolumn{5}{|l|}{ High cholesterol } \\
\hline No & 50.9 & {$[42.3-59.4]$} & 249 & 0.333 \\
\hline Yes & 42.9 & {$[29.8-57.1]$} & 76 & \\
\hline \multicolumn{5}{|l|}{ Cardiovascular disease } \\
\hline No & 46.9 & {$[38.8-55.2]$} & 260 & 0.21 \\
\hline Yes & 58.0 & {$[42.0-72.4]$} & 65 & \\
\hline \multicolumn{5}{|c|}{ Accessed health care in past 5 years } \\
\hline No & 47.2 & {$[37.1-57.5]$} & 142 & 0.658 \\
\hline Yes & 50.4 & {$[40.1-60.6]$} & 183 & \\
\hline \multicolumn{5}{|l|}{ Clinician-assessed vision loss } \\
\hline No & 44.8 & {$[36.0-53.8]$} & 228 & 0.06 \\
\hline
\end{tabular}


Table 2 (continued)

\begin{tabular}{llllll}
\hline & \multicolumn{4}{l}{$\begin{array}{l}\text { Had an eye examination } \\
\text { since diabetes diagnosis }\end{array}$} \\
\cline { 2 - 6 } & $\%$ & $\mathbf{9 5 \%} \mathbf{C l}$ & $\mathbf{n}$ & $\mathbf{p ~ v a l u e}$ \\
\hline Yes & 59.1 & {$[46.4-70.7]$} & 97 & \\
Self-reported vision problems & & & & \\
No & 47.4 & {$[37.2-57.8]$} & 184 & 0.628 \\
Yes & 51.2 & {$[40.2-62.1]$} & 141 & \\
Diabetic medication use & & & & \\
No medication & 35.2 & {$[20.8-53.0]$} & 53 & 0.056 \\
Oral glycaemic medication & 46.6 & {$[36.2-57.3]$} & 178 & \\
Insulin & 64.3 & {$[20.7-92.6]$} & 12 & \\
Insulin and oral glycaemic medica- & 66.9 & {$[54.1-77.6]$} & 82 & \\
tion & & & & & \\
Years since diabetes diagnosis & & & & & \\
0-5 years & 33.0 & {$[23.9-43.5]$} & 148 & $<0.001$ \\
6-10 years & 68.2 & {$[50.4-81.9]$} & 50 & \\
11-20 years & 66.0 & {$[49.3-79.5]$} & 63 & \\
$>$ 20 years & 64.4 & {$[48.8-77.4]$} & 64 & \\
\hline
\end{tabular}

$\mathrm{OR}$, odds ratio; $\mathrm{Cl}$, confidence interval; $\mathrm{n}$, number of participants; ref, reference group

The final adjusted Model 3 (AIC: 654052.6, Prob $>\mathrm{F}=0.008)$, included predisposing, enabling and need factors. Older age (55-64 years OR $=4.18$, $\mathrm{p}=0.003$ and $\geq 65$ years $\mathrm{OR}=4.78, \mathrm{p}=0.002$ compared with 15-44 years), having health insurance $(\mathrm{OR}=6.32$, $\mathrm{p}=0.002)$, and having had diabetes for 6-10 years $(\mathrm{OR}=4.23, \mathrm{p}=0.005$ compared with $0-5$ years $)$ were significantly associated with having had an eye examination. However, being overweight $(\mathrm{OR}=0.38, \mathrm{p}=0.034$ compared with normal-weight or underweight) was significantly associated with reduced odds of having had an eye examination.

\section{Discussion}

This study presents data on the pattern of utilization of eye care services among people with diabetes in South Africa using data from a population-based national survey (SANHANES-1). Almost half of the persons who self-reported diabetes had accessed eye care services since diabetes diagnoses. Older age, having health insurance and duration of diabetes were associated with an increased likelihood of having an eye examination in this study. However, being overweight was associated with a decreased likelihood of having an eye exam among participants with self-reported diabetes.

The rates of eye care utilization among people with diabetes have been reported in different populationbased studies [9-12]. For example, in the United States, both Benoit et al. [9] and MacLennan et al. [13] reported that nearly half of all patients with diabetes had not had an eye exam in over 5 years. In a hospital-based study in India, Sreenivas et al. [12] reported that about a third of diabetic patients sampled had accessed eye care services in the last 1 year. In Tanzania, Mumba et al. [11] reported that about $60 \%$ of diabetic patients sampled had undergone a dilated eye exam after their diagnosis. It is clear that the pattern of utilization varies in different countries and the barriers or factors that promote utilization are also varied.

Consistent with previous studies [9, 13, 14], older age was associated with eye care utilization among people with diabetes. Specifically, people aged 55 years and above were more likely to utilize eye care services. This may be attributed to the compounding effects of increasing resistance to insulin and dysfunction of the pancreatic islets with aging [15], thus diabetes often affects older people more than young people [16].

Having health insurance influences eye care utilization among people with diabetes $[13,17]$. For instance, Mier et al. [18] reported that people with diabetes with medical insurance cover were five times more likely to utilize eye care services than those who did not have insurance. Contrary to most studies (including ours), a study in China reported that the absence of medical insurance cover does not serve as a barrier for eye care utilization among diabetes [10]. Diabetic eye exams in China are affordable and so the availability or otherwise of medical insurance is not a predictive factor for uptake of eye care services [10]. South Africa has both private and public health insurance systems. The public health insurance system primarily serves a large proportion of the population, but like in most developing countries, it is continually underfunded and understaffed. The Medical Aid Schemes Act introduced in 2004 [19] recommends that all medical aids are required by law to cover the cost of treatment and care of diabetes. These benefits, known as Prescribed Minimum Benefits, ensure that members of schemes have access to minimum health services.

Diabetes duration is also a major factor in eye care utilization among people with diabetes. We found that diabetes duration of 6-10 years was significantly associated with increased uptake of eye examination after adjusting for confounders. Longer diabetes duration is known to be associated with increased prevalence/incidence of retinopathy $[20,21]$ and thus an increased need for an eye examination by an eye care professional. It is recommended that persons with diabetes perform a yearly eye examination. The Ophthalmological Society of South Africa's (OSSA) recommended guideline for a diabetic eye exam is that every patient must have a dilated retinal examination at least once every year to screen for diabetic retinopathy [22]. 
Table 3 Multiple logistic regression of having an eye examination since diabetes diagnosis and related factors

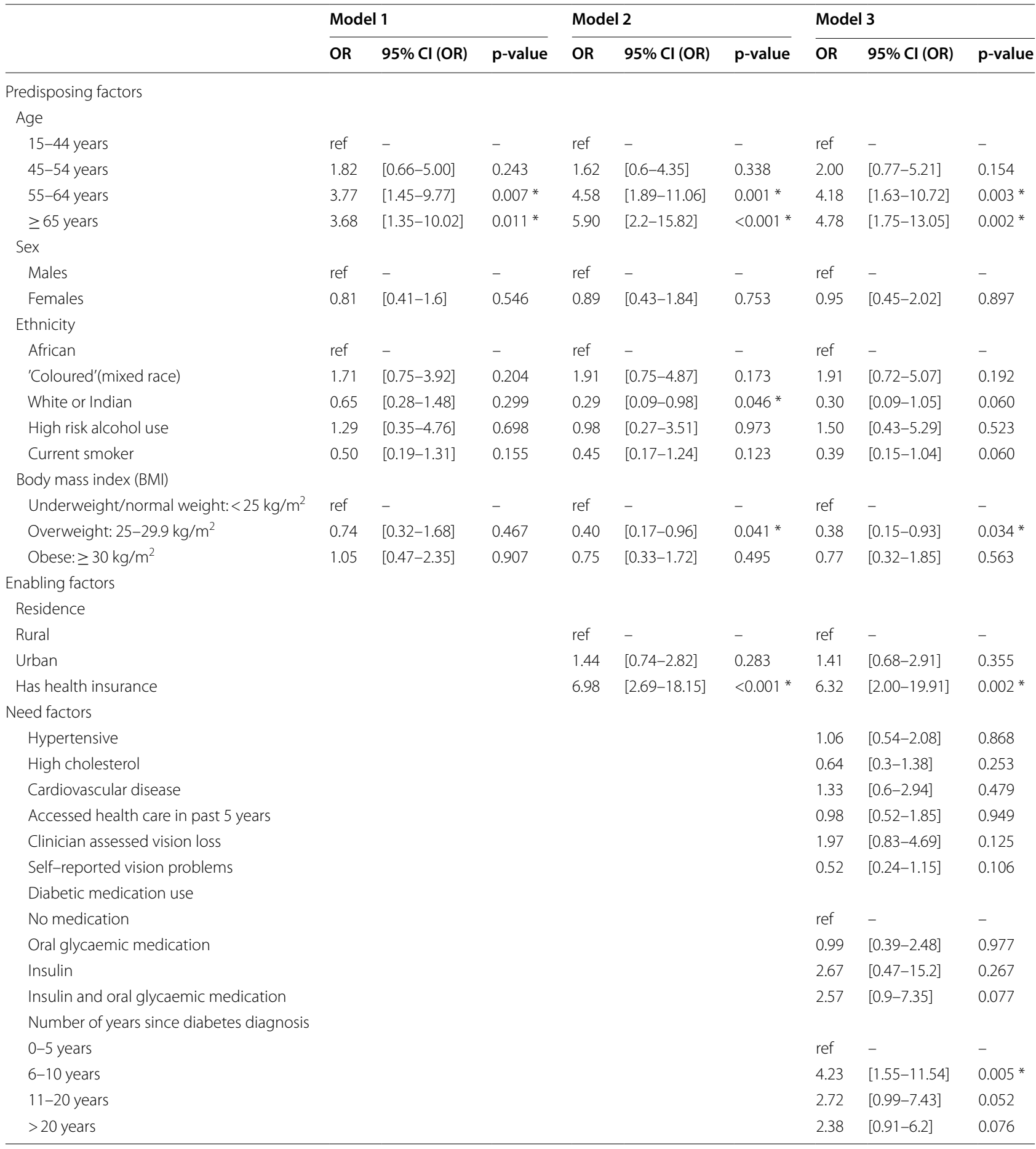

$\mathrm{OR}$, Odds ratio; $\mathrm{Cl}$, confidence interval; $\mathrm{n}$, number of participants; ref, reference group; ${ }^{*}$, statistically significant $\mathrm{p}$ values $(\mathrm{p}<0.05)$

We found that being overweight was a barrier to eye care service utilization. This unanticipated finding, however, has been previously reported by Baumeister et al. [17] who found poor eye care service utilization among overweight people due to very minimal physical activity. Sedentary lifestyle, particularly in individuals whose work requires many hours seated and working on computers, has been associated with obesity, which in turn may lead 
to diabetes. Lack of exercise and physical activity might even form barriers to consulting with a physician. Overweight persons may be discouraged to seek care because of numerous factors. Among these are inadequate medical equipment (e.g.: small/ill-fitting blood pressure cuffs), and dismissive attitudes among healthcare professionals in the form of attribution of all medical problems to weight.

In conclusion, should our sample be representative of the population; our findings suggest that less than half of the diabetic population in South Africa are accessing eye care services. This is worryingly low given the impact of diabetes on vision.

\section{Limitations}

Our study had a few limitations. Firstly, the data on eye exam since diagnosis, self-reported cardiovascular disease conditions, and cholesterol may be subject to recall bias. Also, hypertension was assessed by self-report as well as blood pressure measures obtained in the physical exam. A second limitation of our study design was that, the percentage of patients who had been utilizing eye care is likely to be underestimated. Based on the international guidelines for diabetic eye exam which requires that people with type 1 diabetes must have annual examinations, beginning 5 years after the onset of their disease while those with Type 2 diabetes should have a prompt examination at the time of diagnosis. However, we only assessed eye care utilization based on whether a participant had ever had an eye examination in the last 1 year without taking into cognizance the number of years since diabetes was diagnosed.

\section{Abbreviations}

HSRC: Human Sciences Research Council; REC: Research Ethics Committee; SANHANES: South African National Health and Nutrition Examination Survey; WHO: World Health Organization.

\section{Acknowledgements}

We thank all the experts that gave technical support in the SANHANES (as they are listed in the SANHANES-1 report). We also extend our gratitude to the community leaders and all the South Africans who participated in the survey.

\section{Authors' contributions}

The authors' contributions were as follows: conceptualization, KOA, RS and AKA; methodology, KOA and RS; formal analysis, RS and KOA; writing-original draft preparation, KOA, AKA, RS, EKA, EAM; writing - review and editing, KOA, AKA, RS, ND, EAM, DBK, EKA, and PR; supervision, KOA, DBK and PR All authors read and approved the manuscript.

\section{Funding}

No specific funding was received by authors for this work. However, the SANHANES-1 survey was funded by the South African Department of Health and the UK Department for International Development (DFID).

\section{Availability of data and materials}

The dataset(s) supporting the conclusions of this article is (are) available on request from the Human Sciences Research Council (HSRC) data research repository via access dataset http://www.hsrc.ac.za/en/research-data/.

\section{Ethics approval and consent to participate}

Ethical approval for the study was obtained from the Research Ethics Committee (REC) of the South African Human Sciences Research Council (HSRC) (REC number: $6 / 16 / 11 / 11)$. The study adhered to the tenets of the Declaration of Helsinki. Informed written consent/assent was obtained from all the survey participants. Written informed consent was obtained from a parent or guardian or caregiver for participants aged below 18 years.

\section{Consent for publication}

Not applicable.

\section{Competing interests}

The authors declare that they have no competing interests.

\section{Author details \\ ${ }^{1}$ Department of Optometry and Visual Science, College of Science, Kwame Nkrumah University of Science and Technology, Kumasi, Ghana. ${ }^{2}$ Health \& Wellbeing, Human and Social Capabilities, Human Sciences Research Council, Cape Town, South Africa. ${ }^{3}$ Usher Institute for Population Health Sciences and Informatics, College of Medicine and Veterinary Medicine, University of Edinburgh, Edinburgh, UK. ${ }^{4}$ Department of Ophthalmology and Visual Sciences, Moran Eye Centre, University of Utah, Salt Lake City, Utah, USA. \\ ${ }^{5}$ Department of Nutrition and Integrative Physiology, University of Utah, Salt Lake City, Utah, USA. ${ }^{6}$ Faculty of Health Sciences, Nelson Mandela University, Port Elizabeth, South Africa.}

Received: 22 July 2020 Accepted: 19 August 2020

Published online: 31 August 2020

\section{References}

1. Beran D. The impact of health systems on diabetes care in low and lower middle income countries. Curr DiabRep. 2015;15(4):20.

2. Yau JW, Rogers SL, Kawasaki R, Lamoureux EL, Kowalski JW, BekT, Chen SJ, Dekker JM, Fletcher A, Grauslund J, et al. Global prevalence and major risk factors of diabetic retinopathy. Diabetes Care. 2012;35(3):556-64.

3. Hall V, Thomsen RW, Henriksen O, Lohse N. Diabetes in Sub Saharan Africa 1999-2011: epidemiology and public health implications. A systematic review. BMC Public Health. 2011;11:564.

4. Harding JJ, Egerton M, van Heyningen R, Harding RS. Diabetes, glaucoma, sex, and cataract: analysis of combined data from two case control studies. Br J Ophthalmol. 1993;77(1):2-6.

5. Tumosa N. Eye disease and the older diabetic. Clin Geriatr Med. 2008;24(3):515-27.

6. Klein R, Klein BE, Moss SE, Cruickshanks KJ. The wisconsin epidemiologic study of diabetic retinopathy. XV. The long-term incidence of macular edema. Ophthalmology. 1995;102(1):7-16.

7. Shisana O, Labadarios D, Rehle T, Simbayi L, Zuma K, Dhansay A, Reddy P, Parker W, Hoosain E, Naidoo P, et al. The South African National Health and Nutrition Examination Survey (SANHANES-1). 2014th ed. Cape Town: HSRC Press; 2014.

8. Andersen RM. Revisiting the behavioral model and access to medical care: does it matter? J Health Soc Behav. 1995;36(1):1-10.

9. Benoit SR, Swenor B, Geiss LS, Gregg EW, Saaddine JB. Eye Care Utilization Among Insured People With Diabetes in the US, 2010-2014. Diabetes Care. 2019;42(3):427-33.

10. Wang D, Ding X, He M, Yan L, Kuang J, Geng Q, Congdon N. Use of eye care services among diabetic patients in urban and rural China. Ophthalmology. 2010;117(9):1755-62.

11. Mumba M, Hall A, Lewallen S. Compliance with eye screening examinations among diabetic patients at a tanzanian referral hospital. Ophthalmic Epidemiol. 2007;14(5):306-10.

12. Sreenivas K, Kamath YS, Mathew NR, Pattanshetty S. A study of eye care service utilization among diabetic patients visiting a tertiary care hospital 
in Coastal Karnataka, southern India. Int J Diabetes Dev Countries. 2018;39(1):24-8.

13. MacLennan PA, McGwin G Jr, Searcey K, Owsley C. Medical record validation of self-reported eye diseases and eye care utilization among older adults. Curr Eye Res. 2013;38(1):1-8.

14. Zhang X, Williams DE, Beckles GL, Gregg EW, Barker L, Luo H, Rutledge SA, Saaddine JB. Diabetic retinopathy, dilated eye examination, and eye care education among African Americans, 1997 and 2004. J Natl Med Assoc. 2009:101(10):1015-21.

15. Yakaryilmaz FD, Ozturk ZA. Treatment of type 2 diabetes mellitus in the elderly. World J Diabetes. 2017;8(6):278-85.

16. Kalyani RR, Golden SH, Cefalu WT. Diabetes and aging: unique considerations and goals of care. Diabetes Care. 2017;40(4):440-3.

17. Baumeister SE, Schomerus G, Andersen RM, Tost F, Markus MR, Volzke H, Jurgens $C$. Trends of barriers to eye care among adults with diagnosed diabetes in Germany, 1997-2012. NMCD. 2015;25(10):906-15.

18. Mier N, Wang X, Smith ML, Irizarry D, Trevino L, Alen M, Ory MG. Factors influencing health care utilization in older Hispanics with diabetes along the Texas-Mexico border. Popul Health Manag. 2012;15(3):149-56.
19. South African Government: Medical Aid Schemes Act In.; 2004.

20. Magliah SF, Bardisi W, Al Attah M, Khorsheed MM. The prevalence and risk factors of diabetic retinopathy in selected primary care centers during the 3-year screening intervals. J Family Med Primary Care. 2018;7(5):975-81.

21. Song P, Yu J, Chan KY, Theodoratou E, Rudan I. Prevalence, risk factors and burden of diabetic retinopathy in China: a systematic review and metaanalysis. J Global Health. 2018;8(1):010803.

22. Cairncross JP, Steinberg WJ, Labuschagne MJ. Prevalence of eye pathology in a group of diabetic patients at National District Hospital Outpatient Department in Bloemfontein, South Africa. Afr J Primary Health Care Family Med. 2017;9(1):e1-7.

\section{Publisher's Note}

Springer Nature remains neutral with regard to jurisdictional claims in published maps and institutional affiliations.
Ready to submit your research? Choose BMC and benefit from:

- fast, convenient online submission

- thorough peer review by experienced researchers in your field

- rapid publication on acceptance

- support for research data, including large and complex data types

- gold Open Access which fosters wider collaboration and increased citations

- maximum visibility for your research: over $100 \mathrm{M}$ website views per year

At BMC, research is always in progress.

Learn more biomedcentral.com/submissions 